Article

\title{
Review of Supply Chain Based Embodied Carbon Estimating Method: A Case Study Based Analysis
}

\author{
Muhandiramge Nimashi Navodana Rodrigo *, Srinath Perera (D), Sepani Senaratne (D) and Xiaohua Jin (D) \\ Centre for Smart Modern Construction, School of Engineering, Design and Built Environment, \\ Western Sydney University, Kingswood, NSW 2747, Australia; srinath.perera@westernsydney.edu.au (S.P.); \\ s.senaratne@westernsydney.edu.au (S.S.); xiaohua.jin@westernsydney.edu.au (X.J.) \\ * Correspondence: n.rodrigo@westernsydney.edu.au
}

check for updates

Citation: Rodrigo, M.N.N.; Perera, S.; Senaratne, S.; Jin, X. Review of Supply Chain Based Embodied Carbon Estimating Method: A Case Study Based Analysis. Sustainability 2021, 13, 9171. https://doi.org/ $10.3390 /$ su13169171

Academic Editor: Jorge de Brito

Received: 15 July 2021

Accepted: 12 August 2021

Published: 16 August 2021

Publisher's Note: MDPI stays neutral with regard to jurisdictional claims in published maps and institutional affiliations.

Copyright: (c) 2021 by the authors. Licensee MDPI, Basel, Switzerland. This article is an open access article distributed under the terms and conditions of the Creative Commons Attribution (CC BY) license (https:// creativecommons.org/licenses/by/ $4.0 /)$.

\begin{abstract}
Carbon estimating plays a vital role in the construction industry. The current focus on introducing zero-carbon construction projects reduces operational carbon, at the expense of Embodied Carbon (EC). However, it is important to reduce overall net carbon emissions. There are various methods to estimate carbon, but the accuracy of these estimates is questionable. This paper reviews a novel methodology, the Supply Chain based Embodied carbon Estimating Method (SCEEM), which was introduced recently to accurately estimate EC in construction supply chains. SCEEM is compared against existing EC estimating methods (Blackbook and eToolLCD) using a case study approach. It is also supplemented with a comprehensive literature review of existing EC methods. The EC values calculated using Blackbook and eToolLCD were mostly higher than SCEEM. Since SCEEM uses actual site data and considers first principles-based value addition method to estimate EC, it is considered accurate. The cross-case analysis revealed that SCEEM provided consistent results. Hence, SCEEM is recommended to accurately estimate EC of any type of project.
\end{abstract}

Keywords: embodied carbon; embodied carbon estimating; Supply Chain based Embodied carbon Estimating Method (SCEEM); Blackbook; eToolLCD

\section{Introduction}

Climatic changes have caused a significant impact on the global community [1], thus resulting in increased temperatures, rises in sea levels, increased water vapour in the atmosphere and melting of glaciers [2]. These climatic changes are heavily influenced by human activities. The United Nations Environment Programme [3] has mentioned that the building sector contributes up to $30 \%$ of global annual greenhouse gas emissions. The Australian building sector accounts for about $36 \%$ of the country's overall carbon emissions [4]. Thus, it signifies that carbon control in buildings has become essential and vital [5].

Life cycle carbon comprises Embodied Carbon (EC) and Operational Carbon (OC). $\mathrm{OC}$ refers to the carbon emissions that occur due to consumption of energy in the building during its operational phase [6]. EC emissions occur throughout all the stages including raw material extraction, manufacturing of materials, transportation, construction at site, deconstruction and disposal at site [7].

In a typical building, approximately $70-80 \%$ of carbon emissions are associated with OC, while the remaining are associated with the EC [8]. However, the type of building has an impact on the OC and EC ratio. For example, a low specification building such as a warehouse does not require heating and cooling, which will contribute to less OC, resulting in the remaining EC emissions being significantly high [7,9]. The road map published by Green Building Council Australia [10] emphasises the importance of reducing overall net carbon emissions, not OC alone.

There are various carbon estimating databases and tools available in the industry. However, the accuracy of the estimates prepared using these databases and tools is quite questionable [11-13]. Pomponi and Moncaster [12] stated that the data quality and the reliability of the EC databases is a source of concern. Haynes [14] noted that it is quite difficult to estimate carbon emissions 
accurately and the calculations are subject to more variability. As a result, Rodrigo et al. [13] introduced an accurate Supply Chain based Embodied carbon Estimating Method (SCEEM) to estimate EC in Construction Supply Chains (CSCs). This paper aims to review SCEEM and compare the EC estimates prepared using SCEEM with other EC databases and tools.

Section 1 is a comprehensive literature review on EC and different methods of estimating carbon followed by identifying the available EC estimating databases and tools along with the new method SCEEM. Afterwards, the research methodology adopted in this study is elaborated in detail. Section 3 discusses how SCEEM could be used to estimate EC followed by a detailed comparison to evaluate the EC estimates prepared using SCEEM and other EC estimating databases and tools. Finally, the conclusions of the study are discussed.

\subsection{EC Estimating}

The novel trend to produce zero carbon buildings, which are more energy efficient, intends to reduce the OC to zero, making the remaining EC component more significant $[9,15-18]$. Therefore, managing and reducing EC plays an important role. In order to manage EC, it must be quantified [19], highlighting the importance of estimating EC. There are several methods to estimate EC, for example, process-based method, Environmentally Extended Input-Output Analysis (EEIOA) method and hybrid method.

The process-based method uses a bottom-up approach to assess the environmental impact of goods and services according to their production process [20]. If the bottom-up approach was considered, it would include aggregation of minute data and represent the values of the entire building [21]. Several studies have used a process-based approach to estimate carbon emissions. Seo and Hwang [22] used a process-based approach to compare the entire life cycle emissions of different residential buildings, single family houses, apartments and multifamily houses, including manufacturing, construction, operation and demolition stages. Mao et al. [20] compared the carbon emissions of buildings built using both traditional and modern construction methods.

In the EEIOA method, input-output tables, which contain information on transactions between various sectors in an economy, are combined with environmental aspects related to energy, greenhouse gas emissions and water, among others [23,24]. This method considers the entire economy as a system and involves any number of inputs from other industry sectors [20,25]. The economic input-output based method uses a top-down method considering not only the direct environmental impact of the product or service but also all indirect impacts involved in the supply chain [26,27]. The study of Wang et al. [28] analysed the $\mathrm{CO}_{2}$ emissions of eight industrial sectors in China, including the construction sector, identifying the in-depth characteristics of the inter-sectoral linkages of $\mathrm{CO}_{2}$ emissions. Similarly, the key sectors contributing to the carbon footprint of the Australian construction industry were identified by Yu et al. [29] using the input-output model; the results revealed that the sectors, 'electricity, gas and water' and 'materials', were the largest contributors between 2009 and 2013. However, there is little focus on time series on input-output analysis of emissions related to the construction industry [30].

The hybrid method combines the comprehensiveness of EEIOA method and the specificity of the process-based method to perform environmental and sustainability related analysis. The hybrid method has been introduced to overcome the shortcomings of both process-based and EEIOA methods [31]. Teh et al. [32] have used the hybrid life cycle assessment method to quantify the carbon footprint of cement and concrete products in Australia. Similarly, a hybrid method was adopted in a study conducted by Teh et al. [33] to model the economy-wide potential use of recycled construction materials in Australia.

\subsection{EC Estimating Databases and Tools}

There are various databases and tools available in the construction industry that could be used to estimate EC. A suitable EC estimating database or tool could be selected based on the availability of details, at which project stage EC estimating takes place, requirements of the project and so forth. The available EC databases and tools are listed in Table 1. 
Table 1. EC estimating databases and tools.

\begin{tabular}{|c|c|c|c|c|c|c|c|c|c|c|}
\hline Type & EC Estimating Tool & $\begin{array}{l}\text { System } \\
\text { Boundary }\end{array}$ & Details & $\begin{array}{l}\text { Estimating } \\
\text { Method }\end{array}$ & Type of Software & $\begin{array}{l}\text { Publicly } \\
\text { Available }\end{array}$ & Free & Location & $\begin{array}{c}\text { Last } \\
\text { Updated }\end{array}$ & Reference \\
\hline \multirow{4}{*}{ Databases } & $\begin{array}{c}\text { Inventory of Carbon and } \\
\text { Energy (ICE) }\end{array}$ & cradle-to-gate & $\mathrm{EC}$ & Process & Excel Sheet & Yes & Yes & UK & 2019 & {$[34]$} \\
\hline & Blackbook & cradle-to-gate & $\mathrm{EC}$ & Process & Book & Yes & No & UK & 2010 & {$[35,36]$} \\
\hline & $\begin{array}{l}\text { Waste Reduction Action Plan } \\
\text { (WRAP) }\end{array}$ & - & $\mathrm{EC}$ & Process & Web Application & $\begin{array}{l}\text { For registered } \\
\text { users }\end{array}$ & Yes & UK & - & [37] \\
\hline & Ecoinvent & cradle-to-gate & $\begin{array}{c}\text { Life Cycle } \\
\text { Analysis } \\
\text { (LCA) }\end{array}$ & Process & Web Application & Yes & No & Switzerland & 2017 & [38] \\
\hline \multirow{11}{*}{ Tools } & $\begin{array}{l}\text { Australian Life Cycle Inventory } \\
\text { (AusLCI) }\end{array}$ & cradle-to-gate & EPD & Process & $\begin{array}{l}\text { Excel Sheets/XML } \\
\text { Format }\end{array}$ & Yes & Yes & Australia & 2016 & [39] \\
\hline & $\begin{array}{c}\text { Environmental Performance in } \\
\text { Construction }(\mathrm{EPiC})\end{array}$ & cradle-to-gate & $\begin{array}{c}\text { Embodied } \\
\text { energy and EC }\end{array}$ & Hybrid & Book & Yes & Yes & Australia & 2019 & [40] \\
\hline & The GreenBook 2020 & $\begin{array}{l}\text { cradle-to-end of } \\
\text { construction }\end{array}$ & $\mathrm{EC}$ & Process & Book & Yes & No & Australia & Nov 2019 & [41] \\
\hline & CapIT Estimator & cradle-to-gate & $\mathrm{EC}$ & Process & $\begin{array}{l}\text { Published as } \\
\text { Blackbook }\end{array}$ & Yes & No & UK & 2011 & {$[42]$} \\
\hline & $\begin{array}{l}\text { French Development Agency } \\
\text { (AFD) Carbon Estimating Tool }\end{array}$ & site-grave & $\mathrm{EC}$ and $\mathrm{OC}$ & Process & - & - & - & France & 2017 & {$[43]$} \\
\hline & GaBi Education Software & cradle-to-grave & LCA & Process & $\begin{array}{c}\text { Software } \\
\text { Application }\end{array}$ & Yes & Yes & Germany & 2017 & {$[44]$} \\
\hline & Tally & cradle-to-grave & LCA & Process & $\begin{array}{l}\text { Add-on Software to } \\
\text { Revit }\end{array}$ & Yes & No & USA & 2021 & [45] \\
\hline & SimaPro & cradle-to-grave & LCA & Process & $\begin{array}{l}\text { Software } \\
\text { Application }\end{array}$ & Yes & No & Netherlands & 2017 & [46] \\
\hline & eToolLCD & cradle-to-grave & LCA & Process & Web Application & Yes & No & Australia & 2010 & [47] \\
\hline & $\begin{array}{l}\text { Embodied Carbon Explorer } \\
\text { (ECE) Tool }\end{array}$ & cradle-to-gate & $\mathrm{EC}$ & EEIOA & Web Application & Yes & No & Australia & 2019 & {$[48]$} \\
\hline & The Footprint Calculator & cradle-to-grave & LCA & Process & Web Application & Yes & No & Australia & 2019 & [49] \\
\hline
\end{tabular}


According to Table 1, it is evident that each database or tool is different from one another. Sinha et al. [50] identified that even after using same materials, similar origins and similar technology, estimates prepared using $\mathrm{GaBi}$ and SimaPro produced different results. According to Rodrigo et al. [13], the current EC estimating databases and tools could result in inaccuracies in EC estimates due to various reasons such as different system boundaries, different geographical locations, lack of standardisation and so forth. Currently, EC estimating is not mandated in Australia, hence, there is no necessity or requirement for construction stakeholders to estimate EC. However, it is extremely important to accurately estimate EC in construction [51] while contributing to the United Nations Sustainable Development Goals (UNSDGs) by reducing global EC emissions. This study reviews an accurate methodology that estimates EC, known as SCEEM.

\subsection{SCEEM: An Accurate Methodology to Estimate EC}

A novel methodology was introduced by Rodrigo et al. [13] to estimate EC in CSCs and it is identified as Supply Chain based Embodied carbon Estimating Method (SCEEM), as illustrated in Figure 1. The conceptual methodology has been developed for cradle-toend of construction; however, depending on the scope of the project, it can be expanded to cradle-to-cradle without any difficulty and it could be applied to any type of project.

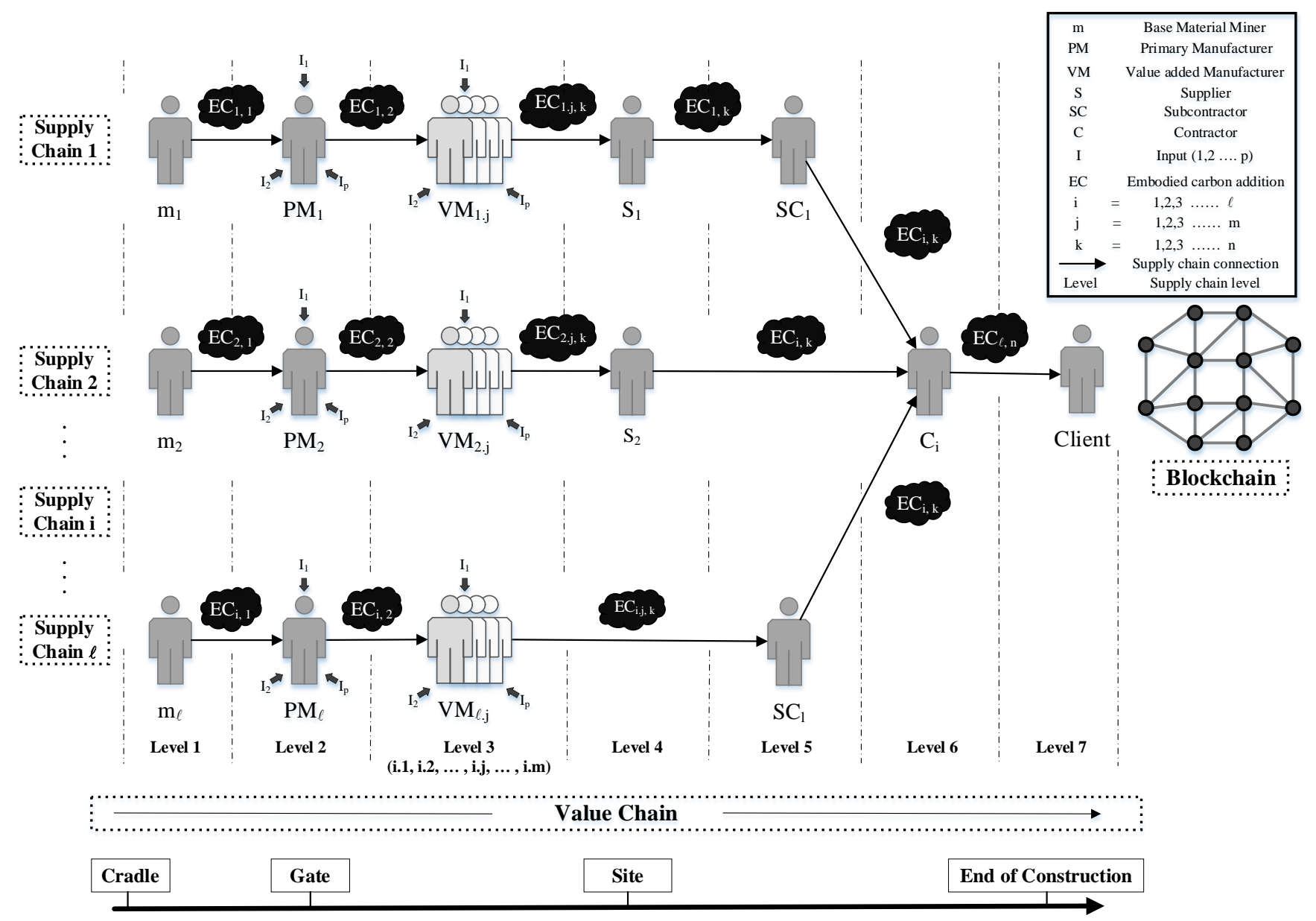

Figure 1. Supply Chain Based Embodied Carbon Estimating Method (SCEEM) [13].

The EC estimating method, SCEEM, as demonstrated in Figure 1, has been developed considering the CSCs. Figure 1 integrates (1) the supply chain concept, where embodied carbon is emitted in CSCs; (2) the value chain concept, where each member in the supply chain adds value at each supply chain node; and (3) blockchain technology, where all supply chain nodes are connected through a peer-to-peer network, contributing to decentralisation. 
Miners, manufacturers, suppliers, subcontractors and contractors are the key stakeholders contributing to EC emissions in a construction project. Manufacturers are broken down into two types: primary manufacturers, who manufacture materials such as cement and steel, among others, and value-added manufacturers, who manufacture products such as pre-cast concrete panels and steel trusses, among others. Therefore, the manufacturers consume different inputs $\left(\mathrm{i}_{1}, \mathrm{i}_{2}, \ldots, \mathrm{i}_{\mathrm{p}}\right)$, as demonstrated in Figure 1.

According to $\mathrm{Hu}$ [52], EC is identified as 'value chain emissions', and includes upstream and downstream emissions. In a CSC, each stakeholder adds a particular value, similarly contributing to $\mathrm{EC}$ emissions $\left(\mathrm{EC}_{1,1}, \mathrm{EC}_{1,2}, \ldots, \mathrm{EC}_{1, \mathrm{n}}\right)$. This philosophical understanding is used in the conceptual methodology to estimate EC in CSCs. Thus, the supply chain, value chain and blockchain can be philosophically connected, as demonstrated in Figure 1. After the EC transactions are recorded on the distributed ledger of the blockchain and validated through the consensus mechanism used by the blockchain platform, they will be shared among all the nodes, enabling decentralisation, immutability, transparency, accuracy, security, trust, etc. Blockchain technology is used to store the EC transactions occurring in CSCs for tracking and monitoring purposes, which is highly beneficial for construction stakeholders. The EC transactions stored in the blockchain cannot be tampered with due to its peer-to-peer network, consensus mechanism and hashing algorithm, which makes it a more secure system. The suitability of using a blockchain-based system instead of a traditional information system has been identified by Rodrigo et al. [53], emphasising the salient features in blockchain technology.

The proposed method, SCEEM, could provide an accurate EC estimate, as it records the actual EC emissions from the EC contributors considering a process-based method while storing and distributing them using blockchain technology. Estimating EC using SCEEM is discussed in detail in Section 2.2.

\section{Research Methodology}

This study aimed to review SCEEM and compare the EC estimates prepared using SCEEM with other EC databases and tools. The research process followed in the study is as demonstrated in Figure 2.

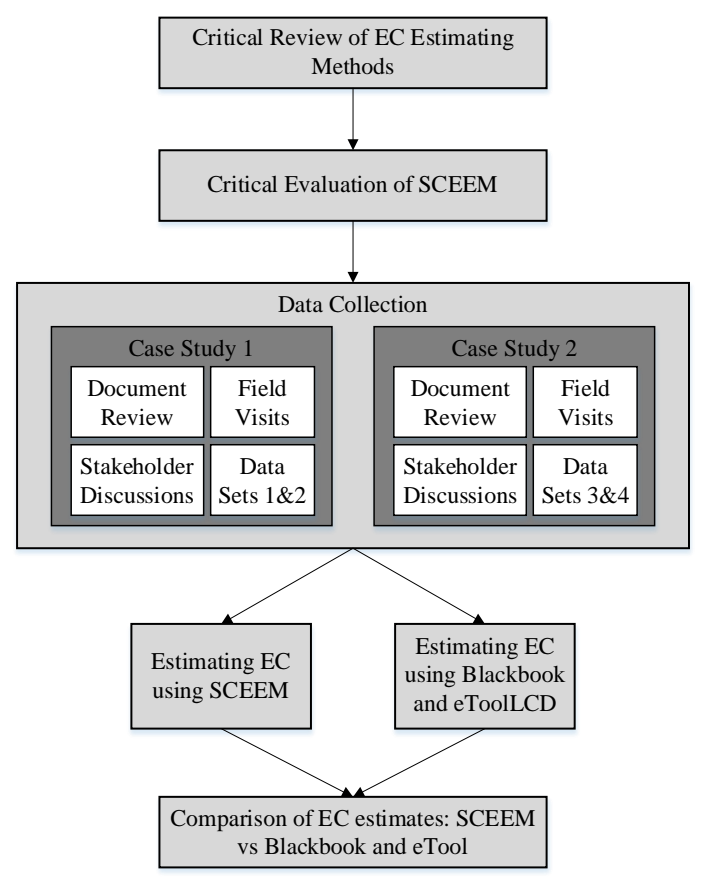

Figure 2. The research process followed in the study.

According to Figure 2, the available EC estimating methods and SCEEM, an accurate methodology developed to estimate EC were reviewed. Subsequently, data were collected 
from two case studies related to housing development projects. The civil construction works within the housing development projects were selected as the scope of the study to evaluate the proof of concept of the study, as other construction works comprise many activities and many CSCs, increasing the complexities. Consequently, EC estimating was carried out using SCEEM, Blackbook and eToolLCD and the estimates were compared with one another.

This study adopted a case study approach as it was required to obtain actual data from sites. On the other hand, the number of case studies was limited to two, due to the limitations of the study such as time and resource constraints, difficulty in data collection from actual sites, lack of maintaining fuel data in sites, lack of maintaining fuel data or hourly usage of equipment by various EC contributors and so forth. Similar studies could be carried out using SCEEM to estimate EC and perform comparisons in other types of projects.

\subsection{Justification for Selection of Databases/Tools}

There are various EC databases and tools, as listed in Table 1, to estimate EC in construction projects. However, due to various reasons, all databases and tools could not be used for estimating EC in the selected case studies in Sydney, Australia. The selection of database/tool depended on whether it contained Australian data or if it accommodated required conversions. Hence, the UK databases Blackbook and ICE, Australian databases AusLCI, EPiC and GreenBook 2020, and Australian tools eTool and ECE Tool were considered for the evaluation as demonstrated in Table 2.

Table 2. Evaluation of reasons for selection of EC databases or tools.

\begin{tabular}{|c|c|c|c|c|c|c|c|c|c|}
\hline$\#$ & Reason & Blackbook & eToolLCD & ICE & $\mathrm{GaBi}$ & $\begin{array}{l}\text { ECE } \\
\text { Tool }\end{array}$ & $\mathrm{EPiC}$ & AusLCI & $\begin{array}{l}\text { GreenBook } \\
2020\end{array}$ \\
\hline 1 & $\begin{array}{c}\text { Availability of EC emission factors } \\
\text { suitable for the data set }\end{array}$ & Yes & Yes & No & No & No & No & No & No \\
\hline 2 & Ease of calculations & Yes & Yes & No & Yes & No & No & No & Yes \\
\hline 3 & Clear and detailed descriptions & Yes & Yes & No & No & No & No & No & Yes \\
\hline 4 & An Australian database $/$ tool & No & Yes & No & No & Yes & Yes & Yes & Yes \\
\hline 5 & $\begin{array}{l}\text { Supports site-to-end of construction } \\
\text { system boundary }\end{array}$ & Yes & Yes & No & No & No & No & No & No \\
\hline 6 & Standalone database / tool & Yes & Yes & Yes & Yes & Yes & Yes & No & Yes \\
\hline 7 & $\begin{array}{l}\text { Use of database/tool by previous } \\
\text { studies and practitioners }\end{array}$ & Yes & Yes & Yes & Yes & No & No & Yes & No \\
\hline 8 & Hybrid approach & No & No & No & No & Yes & Yes & No & Yes \\
\hline 9 & $\begin{array}{l}\text { Possibility of issues related to } \\
\text { double counting }\end{array}$ & No & No & No & No & Yes & Yes & No & Yes \\
\hline
\end{tabular}

The data sets were related to civil works of two housing development projects. The databases and tools, except for Blackbook and eToolLCD, did not have the EC emission factors suitable for the items in the data sets. Hence, the database Blackbook and the tool eToolLCD were used for this study to estimate EC. Other than that, Blackbook and eToolLCD provided EC emission factors in the form of BOQ items with clear detailed descriptions, making it extremely easy to carry out EC calculations. eToolLCD is an Australian tool while Blackbook is UK-based. However, Blackbook has location factors to convert the calculations to be suitable to Sydney, Australia. Both are standalone and provide data related to cradle-to-end of construction system boundary. Several studies including those of Fernando et al. [54] and Victoria et al. [55] have used Blackbook to estimate EC, while a survey carried out by Fouche and Crawford [56] identified that eToolLCD is the second most popular tool in Australia, only $4 \%$ behind the most popular tool, SimaPro. Both Blackbook and eToolLCD have considered a process-based approach to develop the databases, which is similar to the method followed in SCEEM. Due to these reasons, Blackbook and eToolLCD were selected to compare with EC values calculated using SCEEM. 


\subsection{Methodology for Estimating EC Using SCEEM}

SCEEM is an EC estimating method that can be used to estimate EC in CSCs, as demonstrated in Figure 1. The conceptual background for the development of SCEEM is elaborately discussed in Section 1.3, while the step-by-step process to estimate EC using SCEEM is explained in this section. Initially, the data were collected from Case Studies 1 and 2 in the forms of document review, field visits, stakeholder discussions and data sets. The document review comprised reviewing the documents related to each project, including Bills of Quantities (BOQs), drawings and specifications. Field visits followed by stakeholder discussions were subsequently carried out to gather project-specific information. Two data sets related to each case study were collected, as demonstrated in Table 3. Both case studies were located in Sydney, Australia, and the same parties were involved in both case studies.

Table 3. Summary of data sets.

\begin{tabular}{cccc}
\hline Data Set & Case Study & Provided By & System Boundary \\
\hline Data Set 1 & Case Study 1 & Civil contractor & Site-to-end of construction \\
Data Set 2 & Case Study 1 & Concrete pipe manufacturer & Gate-to-site \\
Data Set 3 & Case Study 2 & Civil contractor & Site-to-end of construction \\
Data Set 4 & Case Study 2 & Concrete pipe manufacturer & Gate-to-site \\
\hline
\end{tabular}

\subsubsection{EC Estimating for Site-to-End of Construction}

Data Set 1 of Case Study 1 and Data Set 3 of Case Study 2 comprised hours of usage of equipment for several items in their respective BOQs along with the average fuel burn rate of equipment, which were provided by the contractor. With these data, the total amount of fuel consumed per work item was calculated. EC emissions related to fuel quantities were calculated using the following equation:

$$
E_{i}=\frac{Q_{i} \times E C F_{i} \times C E F_{i}}{1000}
$$

where $E_{i}$ is the carbon emissions of $i$-th fuel type $\left(\mathrm{CO}_{2}\right.$-e tonnes), $Q_{i}$ is the quantity of $i$-th fuel type (kilolitres), $E C F_{i}$ is the energy content factor of $i$-th fuel type (gigajoules per kilolitre) and $C E F_{i}$ is the carbon emission factor for $i$-th fuel type $\left(\mathrm{kgCO}_{2} \mathrm{e}\right.$ per gigajoule). (Source: Department of the Environment and Energy [57].)

All equipment used in the items related to Data Set 1 and Data Set 3 consumed diesel. According to the Department of the Environment and Energy [57], the energy carbon factor and carbon emission factor for diesel are $38.6 \mathrm{GJ} / \mathrm{k} \lambda$ and $69.9 \mathrm{kgCO}_{2} \mathrm{e} / \mathrm{GJ}$, respectively. The detailed calculations carried out using SCEEM to estimate EC for one item in Case Study 1 related to 'removal of topsoil and stockpile for reuse on site', as illustrated in Table 4.

Table 4. EC estimating for topsoil using SCEEM.

\begin{tabular}{|c|c|c|c|c|c|c|c|}
\hline Item & $\begin{array}{l}\text { Plant and } \\
\text { Equipment }\end{array}$ & $\begin{array}{l}\text { No. of } \\
\text { Hours }\end{array}$ & $\begin{array}{l}\text { Fuel Burn } \\
\text { Rate }(\lambda / \mathrm{hr})\end{array}$ & $\begin{array}{l}\text { Fuel } \\
(\mathbf{k} \lambda)\end{array}$ & $\begin{array}{c}\text { ECF } \\
(G J / k \lambda)\end{array}$ & $\begin{array}{c}\mathrm{CEF} \\
\left(\mathrm{kgCO}_{2} \mathrm{e} / \mathrm{GJ}\right)\end{array}$ & $\begin{array}{c}\mathrm{EC} \\
\left(\mathrm{kgCO}_{2} \mathrm{e}\right)\end{array}$ \\
\hline $\begin{array}{l}\text { Strip topsoil from all construction areas } \\
(200 \mathrm{~mm}) \text { average depth, and stockpile for } \\
\text { reuse on site }\end{array}$ & $\begin{array}{l}\text { Cat } 627 \mathrm{G} \text { scraper } \\
\text { Cat } 140 \mathrm{M} \text { grader } \\
\text { Cat } 613 \text { watercart }\end{array}$ & $\begin{array}{l}477.00 \\
120.00 \\
238.00\end{array}$ & $\begin{array}{l}48.85 \\
16.50 \\
14.55\end{array}$ & $\begin{array}{l}23.30 \\
1.98 \\
3.46\end{array}$ & $\begin{array}{l}38.6 \\
38.6 \\
38.6\end{array}$ & $\begin{array}{l}69.9 \\
69.9 \\
69.9\end{array}$ & $\begin{array}{c}62,871 \\
5342 \\
9343 \\
77,556\end{array}$ \\
\hline
\end{tabular}

Similarly, EC values were estimated for all the items in Data Set 1 and Data Set 3 using the process explained for SCEEM.

\subsubsection{EC Estimating in CSCs for Cradle-to-End of Construction}

Data Sets 1 and 3 covered the system boundary site-to-end of construction. One of the items, 'installation of stormwater pipes', contained EC emissions related to its CSC covering cradle-to-end of construction. Hence, this item was selected to explore the suitability of 
SCEEM to estimate EC in CSCs. Therefore, Data Set 2 of Case Study 1 and Data Set 4 of Case Study 2 were collected, which covered the system boundary of cradle-to-site. Considering the item 'installation of stormwater pipes', it was required to collect data from manufacturers, logistics suppliers and raw material extractors, as illustrated in Figure 3.

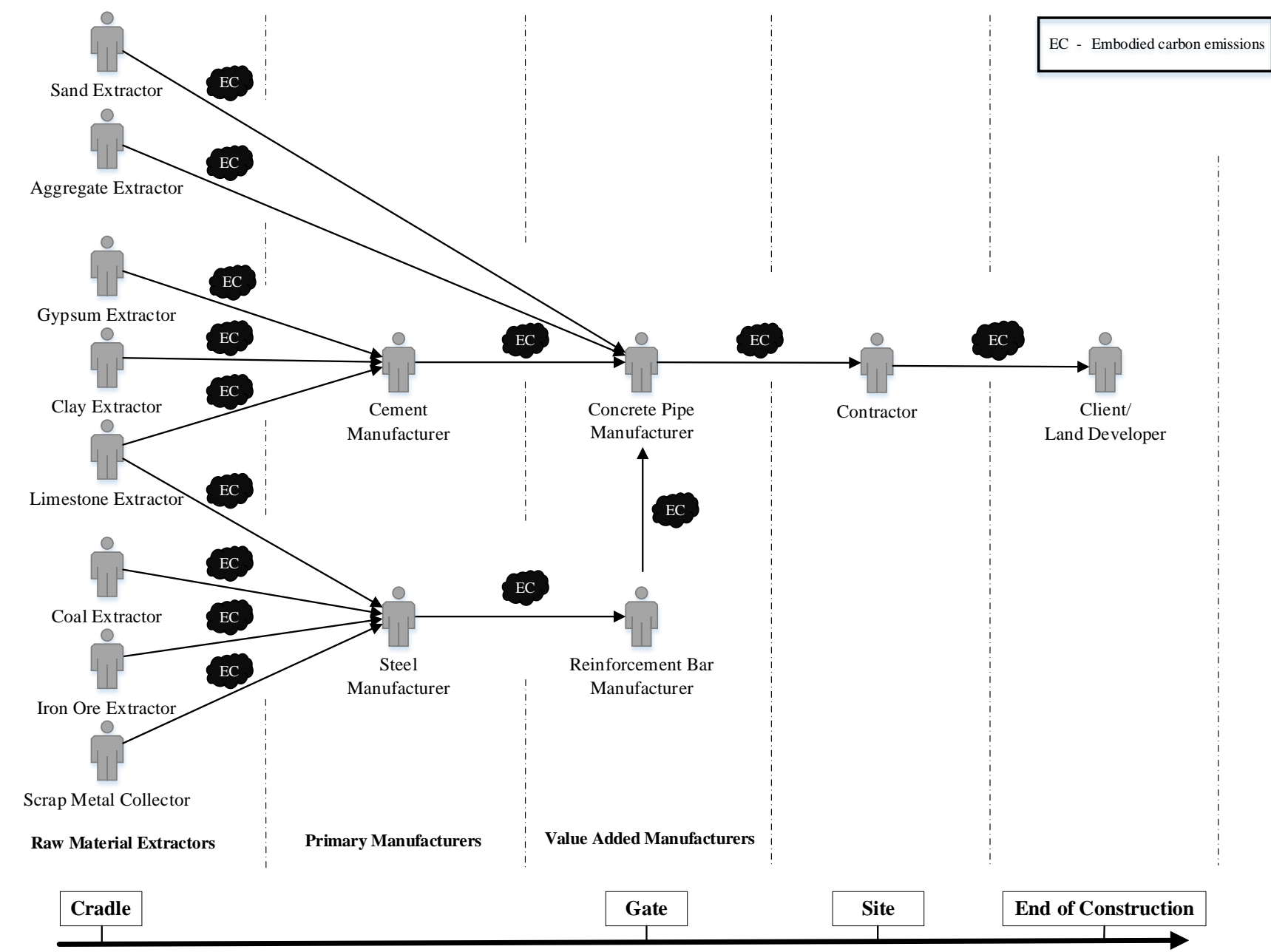

Figure 3. EC contributors for the item 'installation of stormwater pipes' in Case Study 1.

Data were collected from the concrete pipe manufacturer and the logistics supplier; however, due to the difficulty of collecting data from other EC contributors, EPDs and literature sources were used. Electricity is consumed by the concrete pipe manufacturer to manufacture concrete pipes. Hence, the electricity usage was multiplied by $0.83 \mathrm{kgCO}_{2} \mathrm{e} / \mathrm{kWh}$, the EC emission factor for purchased electricity in New South Wales (NSW) [57] to estimate EC emissions contributed by the concrete pipe manufacturer. The EC emissions contributed by the logistics supplier to transport concrete pipes from the manufacturer's factory to the site was estimated using Equation (1) as the fuel (diesel) quantity consumed by the trucks was provided. The EPDs published by various product manufacturers (aggregate extractor, cement manufacturer and reinforcement bar manufacturer) were obtained from EPD Australasia [58] and the EC emission factor to extract sand, which was published by Flower and Sanjayan [59], was used for carrying out the respective EC calculations. The EC values related to each EC contributor in Case Study 1 and the sources used to collect data are listed in Table 5. 
Table 5. EC emissions related to installation of stormwater pipes in Case Study 1 for cradle-to-end of construction using SCEEM.

\begin{tabular}{|c|c|c|c|c|c|c|}
\hline System Boundary & EC Contributor & Description & Quantity & Unit & $\begin{array}{c}\mathrm{EC} \\
\left(\mathrm{kgCO}_{2} \mathrm{e}\right)\end{array}$ & Source \\
\hline \multirow{5}{*}{ Cradle-to-gate } & \multirow{5}{*}{ Sand Extractor } & $375 \mathrm{~mm}$ dia. & 6698 & $\mathrm{~m}$ & 11,277 & \multirow{5}{*}{$\begin{array}{l}\text { Flower and } \\
\text { Sanjayan [59] }\end{array}$} \\
\hline & & $450 \mathrm{~mm}$ dia. & 3037 & $\mathrm{~m}$ & 7363 & \\
\hline & & $525 \mathrm{~mm}$ dia. & 326 & $\mathrm{~m}$ & 993 & \\
\hline & & $675 \mathrm{~mm}$ dia. & 617 & $\mathrm{~m}$ & 2793 & \\
\hline & & 750 mm dia. & 133 & $\mathrm{~m}$ & 718 & \\
\hline \multirow{5}{*}{$\begin{array}{c}\text { Cradle-to-gate (includes } \\
\text { extraction of gravel; } \\
\text { production of aggregate; and } \\
\text { transportation) }\end{array}$} & \multirow{5}{*}{$\begin{array}{l}\text { Aggregate } \\
\text { Extractor }\end{array}$} & $375 \mathrm{~mm}$ dia. & 6698 & $\mathrm{~m}$ & 29,206 & \multirow{5}{*}{ Repurpose It [60] } \\
\hline & & $450 \mathrm{~mm}$ dia. & 3037 & $\mathrm{~m}$ & 19,069 & \\
\hline & & $525 \mathrm{~mm}$ dia. & 326 & $\mathrm{~m}$ & 2572 & \\
\hline & & $675 \mathrm{~mm}$ dia. & 617 & $\mathrm{~m}$ & 7234 & \\
\hline & & $750 \mathrm{~mm}$ dia. & 133 & $\mathrm{~m}$ & 1859 & \\
\hline \multirow{5}{*}{$\begin{array}{l}\text { Cradle-to-gate (includes } \\
\text { extraction of gypsum, clay } \\
\text { and limestone; and } \\
\text { transportation) }\end{array}$} & \multirow{5}{*}{$\begin{array}{c}\text { Cement } \\
\text { Manufacturer }\end{array}$} & 375 mm dia. & 6698 & $\mathrm{~m}$ & 363,486 & \multirow{5}{*}{ Holcim [61] } \\
\hline & & $450 \mathrm{~mm}$ dia. & 3037 & $\mathrm{~m}$ & 237,329 & \\
\hline & & $525 \mathrm{~mm}$ dia. & 326 & $\mathrm{~m}$ & 32,002 & \\
\hline & & 675 mm dia. & 617 & $\mathrm{~m}$ & 90,030 & \\
\hline & & 750 mm dia. & 133 & $\mathrm{~m}$ & 23,137 & \\
\hline \multirow{5}{*}{$\begin{array}{l}\text { Cradle-to-gate (includes } \\
\text { extraction of limestone, coal } \\
\text { and iron ore; collection of } \\
\text { strap metal; manufacturing } \\
\text { of steel; and transportation) }\end{array}$} & \multirow{5}{*}{$\begin{array}{l}\text { Reinforcement } \\
\text { bar Manufacturer }\end{array}$} & $375 \mathrm{~mm}$ dia. & 6698 & $\mathrm{~m}$ & 236,616 & \multirow{5}{*}{$\begin{array}{c}\text { BlueScope Steel } \\
{[62]}\end{array}$} \\
\hline & & $450 \mathrm{~mm}$ dia. & 3037 & $\mathrm{~m}$ & 154,492 & \\
\hline & & $525 \mathrm{~mm}$ dia. & 326 & $\mathrm{~m}$ & 20,833 & \\
\hline & & $675 \mathrm{~mm}$ dia. & 617 & $\mathrm{~m}$ & 58,606 & \\
\hline & & 750 mm dia. & 133 & $\mathrm{~m}$ & 15,061 & \\
\hline \multirow{6}{*}{ Gate } & \multirow{5}{*}{$\begin{array}{l}\text { Concrete Pipe } \\
\text { Manufacturer }\end{array}$} & $375 \mathrm{~mm}$ dia. & 6698 & $\mathrm{~m}$ & 357,281 & \multirow{5}{*}{$\begin{array}{l}\text { Concrete Pipe } \\
\text { Manufacturer }\end{array}$} \\
\hline & & $450 \mathrm{~mm}$ dia. & 3037 & $\mathrm{~m}$ & 230,208 & \\
\hline & & $525 \mathrm{~mm}$ dia. & 326 & $\mathrm{~m}$ & 33,254 & \\
\hline & & $675 \mathrm{~mm}$ dia. & 617 & $\mathrm{~m}$ & 84,878 & \\
\hline & & $750 \mathrm{~mm}$ dia. & 133 & $\mathrm{~m}$ & 21,533 & \\
\hline & \multirow{5}{*}{ Logistics Supplier } & $375 \mathrm{~mm}$ dia. & 6698 & $\mathrm{~m}$ & 18,423 & \multirow{5}{*}{ Logistics Supplier } \\
\hline \multirow{4}{*}{ Gate-to-site } & & $450 \mathrm{~mm}$ dia. & 3037 & $\mathrm{~m}$ & 11,081 & \\
\hline & & $525 \mathrm{~mm}$ dia. & 326 & $\mathrm{~m}$ & 1202 & \\
\hline & & $675 \mathrm{~mm}$ dia. & 617 & $\mathrm{~m}$ & 3471 & \\
\hline & & 750 mm dia. & 133 & $\mathrm{~m}$ & 801 & \\
\hline Site-to-end of construction & Contractor & $\begin{array}{l}\text { Excavate, backfill } \\
\text { and compact } \\
\text { trenches }\end{array}$ & 16,714 & $\mathrm{~m}^{3}$ & 76,980 & Contractor \\
\hline
\end{tabular}

The same data collection process was followed to collect data related to Data Set 3 and Data Set 4 in Case Study 2. The EC emissions related to manufacturing of plant and equipment applicable for the selected case studies were less than $1 \%$ of EC emissions contributed by the plant and equipment used for the item. Therefore, it was disregarded from the scope of this study.

Several issues were identified while estimating EC using SCEEM, but these could be resolved quite easily. For example, though the expectation was to collect fuel data from the contractor, the contractor had maintained hours of usage of equipment, instead of fuel quantities. Therefore, the hours had to be converted to fuel by multiplying the number of hours with the fuel burn rate of the respective plant and equipment. This was one of the challenges faced, but it was not difficult to resolve.

\subsection{Methodology for Estimating EC Using Blackbook}

Blackbook is a published book comprising EC emission factors for various items in the format of a BOQ considering the system boundary of cradle-to-gate [36]. However, though the items in Data Set 1 and 3 are related to site-to-end of construction, Blackbook has provided EC emission factors for these items. For example, excavation of topsoil is an activity carried out at site, therefore, if Blackbook provides only items for cradle-to-gate, it should not have an EC emission factor for such items. This indicates that Blackbook could 
be used for the system boundary of site-to-end of construction by evaluating the scope of the item in detail. Therefore, Blackbook could be used for this study.

EC estimating using Blackbook was carried out in several steps. The step-by-step process to estimate using Blackbook is explained for the same item, which was previously considered for SCEEM in Section 2.1. As there was no item for $200 \mathrm{~mm}$ thick topsoil, the rate given for $300 \mathrm{~mm}$ thick top soil was considered and a prorate basis calculation was carried out to find the suitable EC emission factor. Subsequently, the quantity of the BOQ item was multiplied by the EC emission factor to estimate the EC emissions related to that item. However, this value is for the UK. In order to convert the UK EC emissions to be suitable for the Australian context, they had to be multiplied by 1.06 [36]. The summary of the calculation process is demonstrated in Table 6.

Table 6. EC estimating for topsoil using Blackbook.

\begin{tabular}{|c|c|c|c|c|c|}
\hline Description & Quantity & Unit & $\begin{array}{l}\text { EC Rate } \\
\left(\mathrm{kgCO}_{2}\right)\end{array}$ & $\begin{array}{c}\text { EC Amount UK } \\
\left(\mathrm{kgCO}_{2}\right)\end{array}$ & $\begin{array}{c}\text { EC Amount } \\
\text { Australia }\left(\mathrm{kgCO}_{2}\right)\end{array}$ \\
\hline $\begin{array}{l}\text { Strip topsoil from all construction areas } \\
(200 \mathrm{~mm}) \text { average depth, and stockpile } \\
\text { for reuse on site }\end{array}$ & 401,724 & $\mathrm{~m}^{2}$ & 0.335 & 134,577 & 142,652 \\
\hline
\end{tabular}

Blackbook was used following the same process to estimate the EC values of the items in the data sets in both case studies.

\subsection{Methodology for Estimating EC Using eToolLCD}

eToolLCD is a web application that is used to estimate Global Warming Potential (GWP) of various projects for the system boundary of cradle-to-cradle. However, Data Set 1 and Data Set 3 included items related to the system boundary of site-to-end of construction, hence, in eToolLCD, for analysis purposes, EC emissions in the construction stage were considered. This indicates that EC values calculated using both SCEEM and eToolLCD for these two data sets have considered the system boundary site-to-end of construction. Subsequently, EC emissions calculated in Case Study 1 and Case Study 2 (including Data Sets 1, 2, 3 and 4) for the system boundary of cradle-to-end of construction was compared with EC values calculated using eToolLCD considering the stages, production, transportation and construction. The EC values were compared considering the suitable system boundaries, as appropriate. The step-by-step process that was carried out to estimate EC using eToolLCD is explained next.

The quantity for the item was obtained from the project BOQ. The quantity given in $\mathrm{m}^{2}$ had to be converted to $\mathrm{m}^{3}$ as the EC emission factor given in eToolLCD was for $100,000 \mathrm{~m}^{3}$. Subsequently, the EC emission factor from eToolLCD, 486,422 $\mathrm{kgCO}_{2} \mathrm{e}$, was divided by $100,000 \mathrm{~m}^{3}$ to find the EC emission factor per $1 \mathrm{~m}^{3}$. Then, the quantity was multiplied by this EC emission factor to calculate the EC value for this item as demonstrated in Table 7.

Table 7. EC estimating for topsoil using eToolLCD.

\begin{tabular}{cccc}
\hline Description & Quantity $\left(\mathbf{m}^{3}\right)$ & $\begin{array}{c}\text { EC Emission Factor } \\
\left.\mathbf{( k g C O}_{\mathbf{2}} \mathbf{e} / \mathbf{m}^{3}\right)\end{array}$ & EC Value (kgCO $\mathbf{e})$ \\
\hline $\begin{array}{c}\text { Strip topsoil from all construction areas }(200 \mathrm{~mm}) \\
\text { average depth, and stockpile for reuse on site }\end{array}$ & 80,345 & 4.864 & 390,815 \\
\hline
\end{tabular}

However, the exact item in the data set could not be found in eToolLCD. On such occasions, the most suitable alternative had to be used. For example, to estimate EC for the item on topsoil, EC emissions related to bulk excavation of earthworks and stockpiling on site was used, as illustrated in Table 7. The same steps were followed to estimate EC for all the items in the data sets. 


\section{Research Findings}

\subsection{Comparison of EC Values: SCEEM vs. Blackbook vs. eToolLCD}

This section provides a comparison between the three methods, SCEEM, Blackbook and eToolLCD. EC estimating carried out using SCEEM should be providing accurate figures as EC emissions occurred from the original sources have been considered. Therefore, comparisons were carried out by considering EC values estimated using SCEEM as the benchmark.

\subsubsection{Case Study 1 for Site-to-End of Construction}

EC values calculated using SCEEM, Blackbook and eToolLCD for Data Set 1 of Case Study 1 is illustrated in Table 8 . The last two columns of Table 8 indicate the percentage difference between SCEEM and Blackbook as well as SCEEM and eToolLCD.

Table 8. Difference of EC values of Case Study 1 estimated using SCEEM, Blackbook and eToolLCD for site-to-end of construction.

\begin{tabular}{|c|c|c|c|c|c|c|c|c|}
\hline \multirow{2}{*}{ Item } & \multirow[t]{2}{*}{ Description } & \multirow[t]{2}{*}{ Quantity } & \multirow{2}{*}{ Unit } & \multicolumn{3}{|c|}{$\mathrm{EC}\left(\mathrm{kgCO}_{2} \mathrm{e}\right)$} & \multicolumn{2}{|c|}{$\begin{array}{l}\text { Difference \% between } \\
\text { SCEEM and }\end{array}$} \\
\hline & & & & SCEEM & Blackbook & eToolLCD & Blackbook & eToolLCD \\
\hline A & $\begin{array}{c}\text { Strip topsoil (200 mm) and stockpile } \\
\text { on site }\end{array}$ & 401,724 & $\mathrm{~m}^{2}$ & 77,556 & 142,794 & 390,815 & 84 & 402 \\
\hline B & $\begin{array}{l}\text { Cart from stockpile and spread } \\
\text { topsoil }(200 \mathrm{~mm})\end{array}$ & 314,022 & $\mathrm{~m}^{2}$ & 71,463 & 35,616 & 132,684 & -50 & 86 \\
\hline $\mathrm{C}$ & $\begin{array}{l}\text { Cart from stockpile and spread } \\
\text { topsoil }(100 \mathrm{~mm})\end{array}$ & 29,695 & $\mathrm{~m}^{2}$ & 9295 & 3368 & 6274 & -64 & -33 \\
\hline $\mathrm{D}$ & Cut to onsite fill & 189,105 & $\mathrm{~m}^{3}$ & 452,004 & 487,297 & 919,848 & 8 & 104 \\
\hline E & Cut and stockpile onsite & 158,384 & $\mathrm{~m}^{3}$ & 159,969 & 337,453 & 770,415 & 111 & 382 \\
\hline $\mathrm{F}$ & $\begin{array}{l}\text { Excavate, backfill and } \\
\text { compact trenches }\end{array}$ & 16,714 & $\mathrm{~m}^{3}$ & 76,980 & 96,061 & 229,765 & 25 & 198 \\
\hline G & Cart surplus materials to stockpile & 7713 & $\mathrm{~m}^{3}$ & 18,480 & 22,459 & 37,518 & 22 & 103 \\
\hline
\end{tabular}

According to Table 8, considering all calculations, the highest EC values were reported from item D. The lowest EC values were resulted from item C. Considering the percentage difference between SCEEM vs. Blackbook, for most of the items, the percentage difference was $50 \%$ or more. For example, the EC value estimated using Blackbook for item E was $111 \%$ higher than the EC value estimated using SCEEM. There might be several reasons for this massive difference. Blackbook did not have EC emission factors for items such as cart from excavation and for stockpiling on site. Therefore, the EC emission factor for excavation for cutting was considered. Similarly, the EC value calculated using Blackbook for item A was $84 \%$ higher than the EC value calculated using SCEEM. The reasons for this massive difference would have been due to the usage of pro-rata basis calculations based on $300 \mathrm{~mm}$ thick topsoil as there was no EC emission factor for $200 \mathrm{~mm}$ thick topsoil, available in Blackbook. These would have led to massive differences between the EC figures.

In almost all of the items, the percentage difference between SCEEM and eToolLCD was more than $50 \%$, except for item $C$, which also indicated a percentage difference of $33 \%$. The highest percentage difference between EC values calculated using SCEEM and eToolLCD was demonstrated by item B with a percentage difference of $402 \%$, which is extremely massive. These massive percentage differences would have resulted due to the comparatively higher EC emission factors available in eToolLCD libraries. For example, the EC emission factor given for item B in Blackbook was only $0.335 \mathrm{kgCO}_{2} \mathrm{e} / \mathrm{m}^{2}$ while the EC emission factor given for this item in eToolLCD was $4.864 \mathrm{kgCO}_{2} \mathrm{e} / \mathrm{m}^{2}$. This would have affected the calculated EC values using eToolLCD emission rates to have massively higher EC values.

The percentage differences between SCEEM and Blackbook was more than $50 \%$ for some of the items. On the other hand, the percentage difference between SCEEM and eToolLCD was more than $50 \%$ for most of the items. The data set is considerably small 
to derive conclusions; however, as SCEEM uses a first principles-based value addition method, it should provide accurate results. Hence, it is recommended to use SCEEM.

3.1.2. Case Study 1 for Cradle-to-End of Construction (Manufacturing, Transporting and Installing Stormwater Pipes)

The item 'installation of stormwater pipes' of Case Study 1 was considered to compare the EC emissions in its CSCs. The calculated EC values for the system boundary of cradle-to-end of construction using SCEEM, Blackbook and eToolLCD are demonstrated in Table 9.

Table 9. Difference of EC values of Case Study 1 estimated using SCEEM, Blackbook and eToolLCD for cradle-to-end of construction.

\begin{tabular}{|c|c|c|c|c|c|c|}
\hline \multirow{2}{*}{$\begin{array}{l}\text { System } \\
\text { Boundary }\end{array}$} & \multirow{2}{*}{ Description } & \multicolumn{3}{|c|}{$\mathrm{EC}\left(\mathrm{kgCO}_{2} \mathrm{e}\right)$} & \multicolumn{2}{|c|}{$\begin{array}{c}\text { Difference } \% \text { between } \\
\text { SCEEM and }\end{array}$} \\
\hline & & SCEEM & Blackbook & eToolLCD & Blackbook & eToolLCD \\
\hline $\begin{array}{l}\text { Cradle-to-end } \\
\text { of construction }\end{array}$ & $\begin{array}{l}\text { Manufacturing, transportation and } \\
\text { installation of stormwater pipes }\end{array}$ & $2,153,775$ & $1,602,285$ & $1,995,610$ & -26 & -7 \\
\hline
\end{tabular}

SCEEM and Blackbook indicated a percentage difference of $26 \%$. Hence, the reason for such a difference was explored. Blackbook did not include EC emission factors for some of the pipes and on such occasions, pro-rata basis calculations were carried out. For example, the EC emission factors for $675 \mathrm{~mm}$ dia and $750 \mathrm{~mm}$ dia concrete RRJ pipes were not available in Blackbook. Hence, the EC emission factor for $600 \mathrm{~mm}$ dia concrete RRJ pipe was considered to carry out pro-rata basis calculations. On the other hand, Blackbook includes UK-based data, hence, a location factor was used to convert it to Australian-based data. Blackbook further states that it has not considered transportation-related data. These would have resulted in different EC values calculated using Blackbook and SCEEM.

The percentage difference between EC values calculated using SCEEM and eToolLCD was only $7 \%$. This indicates that SCEEM and eToolLCD provide approximately close results for this item. SCEEM uses a first principles-based value addition method to estimate EC and it should provide accurate results. Therefore, instead of using existing EC estimating databases and tools, SCEEM can be recommended for estimating EC.

\subsubsection{Case Study 2 for Site-to-End of Construction}

EC values calculated for the items in Data Set 3 using SCEEM, Blackbook and eToolLCD are demonstrated in Table 10.

Table 10. Difference of EC values of Case Study 2 estimated using SCEEM, Blackbook and eToolLCD for site-to-end of construction.

\begin{tabular}{|c|c|c|c|c|c|c|c|c|}
\hline \multirow{2}{*}{ Item } & \multirow{2}{*}{ Description } & \multirow{2}{*}{ Quantity } & \multirow{2}{*}{ Unit } & \multicolumn{3}{|c|}{$\mathrm{EC}\left(\mathrm{kgCO}_{2} \mathrm{e}\right)$} & \multicolumn{2}{|c|}{$\begin{array}{l}\text { Difference } \% \text { between } \\
\text { SCEEM and }\end{array}$} \\
\hline & & & & SCEEM & Blackbook & eToolLCD & Blackbook & eToolLCD \\
\hline A & $\begin{array}{l}\text { Strip topsoil (250 mm) and stockpile } \\
\text { on site }\end{array}$ & 97,434 & $\mathrm{~m}^{2}$ & 23,581 & 43,261 & 118,486 & 84 & 402 \\
\hline B & $\begin{array}{l}\text { Cart from stockpile and spread } \\
\text { topsoil }(300 \mathrm{~mm})\end{array}$ & 78,925 & $\mathrm{~m}^{2}$ & 26,048 & 8919 & 50,023 & -66 & 92 \\
\hline C & $\begin{array}{l}\text { Cart from stockpile and spread } \\
\text { topsoil }(150 \mathrm{~mm})\end{array}$ & 12,513 & $\mathrm{~m}^{2}$ & 5917 & 1414 & 3966 & -76 & -33 \\
\hline $\mathrm{D}$ & Cut to onsite fill & 7398 & $\mathrm{~m}^{3}$ & 17,797 & 19,065 & 35,986 & 7 & 102 \\
\hline E & $\begin{array}{l}\text { Excavate, backfill and } \\
\text { compact trenches }\end{array}$ & 1899 & $\mathrm{~m}^{3}$ & 8319 & 10,914 & 26,106 & 31 & 214 \\
\hline $\mathrm{F}$ & Cart surplus materials to stockpile & 1688 & $\mathrm{~m}^{3}$ & 4030 & 4916 & 8211 & 22 & 104 \\
\hline
\end{tabular}

According to Table 10, the highest percentage difference between SCEEM and Blackbook as well as SCEEM and eToolLCD was indicated by item A, 'strip topsoil ( $250 \mathrm{~mm}$ ) and stockpile on site', which are $84 \%$ and $402 \%$, respectively. The reasons for this massive differ- 
ence related to Blackbook would have been due to the usage of pro-rata basis calculations considering $300 \mathrm{~mm}$ thick topsoil given in Blackbook, as there was no EC emission factor for $250 \mathrm{~mm}$ thick topsoil. The EC values calculated for items B and C using Blackbook were $66 \%$ and $76 \%$ less than EC values calculated using SCEEM, respectively. These great differences would have been caused due to the unavailability of EC emission factor for cart from stockpile in Blackbook. As a result, only spread of topsoil and compaction have been considered to estimate EC of these two items using Blackbook. The percentage differences for the other items in Data Set 3 were between $7 \%$ and $31 \%$. These differences were less compared to the massive differences indicated by the other items.

The EC values calculated using eToolLCD for the items in Data Set 3 were massively higher than the EC values calculated using SCEEM, except for the item, C, on 'cart from stockpile and spread topsoil $(150 \mathrm{~mm})^{\prime}$, which was $33 \%$ less than its EC value calculated using SCEEM. The reason for such massive differences would have been due to eToolLCD having massive EC emission factors for these items, when compared with EC emission factors of Blackbook, as explained in detail in Section 3.1.1. Therefore, the EC values calculated using SCEEM and eToolLCD for the items in Data Set 3 were somewhat different.

For $50 \%$ of the items in Data Set 3, the percentage differences between SCEEM and Blackbook were more than $50 \%$. The percentage difference between SCEEM and eToolLCD was higher for most of the items in Data Set 3. As SCEEM uses a first principles-based method to estimate EC, the EC values calculated using SCEEM should be accurate. Hence, it is recommended to use SCEEM for estimating EC in CSCs.

3.1.4. Case Study 2 for Cradle-to-End of Construction (Manufacturing, Transporting and Installing Stormwater Pipes)

Comparisons of EC emissions carried out between SCEEM and Blackbook and between SCEEM and eToolLCD for the item 'installation of stormwater pipes' in Case Study 2 (including Data Set 3 and Data Set 4) considering cradle-to-end of construction is presented in Table 11.

Table 11. Difference of EC values of Case Study 2 estimated using SCEEM, Blackbook and eToolLCD for cradle-to-end of construction.

\begin{tabular}{|c|c|c|c|c|c|c|}
\hline \multirow{2}{*}{$\begin{array}{l}\text { System } \\
\text { Boundary }\end{array}$} & \multirow{2}{*}{ Description } & \multicolumn{3}{|c|}{$\mathrm{EC}\left(\mathrm{kgCO}_{2} \mathrm{e}\right)$} & \multicolumn{2}{|c|}{$\begin{array}{l}\text { Difference \% between } \\
\text { SCEEM and }\end{array}$} \\
\hline & & SCEEM & Blackbook & eToolLCD & Blackbook & eToolLCD \\
\hline $\begin{array}{l}\text { Cradle-to-end } \\
\text { of construction }\end{array}$ & $\begin{array}{l}\text { Manufacturing, transportation and } \\
\text { installation of stormwater pipes }\end{array}$ & 244,460 & 182,028 & 226,656 & -26 & -7 \\
\hline
\end{tabular}

The percentage difference between SCEEM and Blackbook was $26 \%$ while the percentage difference between SCEEM and eToolLCD was only $7 \%$. The reason for Blackbook to have such a massive difference was explored. Similar to the issues identified in Section 3.1.2, when estimating EC using Blackbook, pro-rata basis calculations were carried out to find suitable EC emission factors for certain items. A location factor available in Blackbook was used to convert the EC values calculated using Blackbook based on UK data to Australian data. Blackbook does not include transportation-related data while SCEEM included transportation-related data, which cannot be separated, to exclude and carry out comparisons. These reasons would have resulted in EC emissions calculated using Blackbook being $26 \%$ lower than EC emissions calculated using SCEEM.

However, SCEEM uses a first principles-based value addition method to estimate EC as illustrated in Section 1.3. Hence, it should provide more accurate results. Therefore, instead of using existing EC estimating databases and tools, SCEEM can be recommended for estimating EC. 


\subsubsection{Cross-Case Analysis-Site-to-End of Construction}

A cross-case analysis carried out between Case Study 1 and Case Study 2 to evaluate the similarities and differences of EC values calculated using SCEEM, Blackbook and eToolLCD for the data collected from the contractor is discussed in this section. Table 12 presents the EC values per unit calculated for the data collected from the contractor considering the system boundary of site-to-end of construction. Furthermore, the last three columns present the percentage difference between Case Study 1 and Case Study 2, which indicate the similarities and differences in each item.

According to Table 12, the highest EC values per unit in both case studies was demonstrated by item F, 'excavate, backfill and compact trenches', for all three methods (SCEEM, Blackbook and eToolLCD). The percentage difference in Blackbook for most of the items between case studies was less than $1 \%$ except for item A, 'strip topsoil and stockpile on site', which indicated a percentage difference of $24.91 \%$. The reason for the difference was explored. The unit of measurement for this item being square metres and the topsoil thickness being different in both case studies have resulted in different percentage differences. For example, in Case Study 1, the topsoil thickness was only $200 \mathrm{~mm}$ while in Case Study 2 , it was $250 \mathrm{~mm}$. However, though items B and C, were measured in square metres, the percentage difference for Blackbook is less than 1\%. The reason for this is that Blackbook did not have an EC emission factor for cart from stockpile and spread topsoil, so the EC emission factor for surface treatment was considered. Surface treatment is measured in square metres and the depth of the topsoil has no impact on it. Hence, the percentage difference of Blackbook was lesser for items B and C.

Both SCEEM and eToolLCD indicated higher percentage differences for the items A, $B$ and $C$. The reason for such a difference would have been due to the differences in the thicknesses of topsoil in the items, where the unit of measurement for all three items was square metres. Hence, the thickness of the topsoil has a significant impact on the EC value per unit. In addition, SCEEM demonstrated such a difference due to the differences in the fuel efficiency between the sites.

In summary, the cross-case analysis carried out on SCEEM revealed that both case studies present similar results for some of the items; however, when estimating EC using fuel quantities, the fuel efficiency of each site could result in differences. However, using SCEEM is the recommended method to estimate EC accurately.

\subsubsection{Cross-Case Analysis-Cradle-to-End of Construction}

This section provides a cross-case analysis between EC values calculated using SCEEM, Blackbook and eToolLCD for a selected example considering its CSCs. Table 13 provides the EC values per unit of measurement for both Case Study 1 and Case Study 2 considering an item related to installation of stormwater pipes for the system boundary of cradle-to-end of construction. The last three columns indicate the percentage difference between the EC per unit of measurement calculated for Case Study 1 and Case Study 2.

According to the findings of Table 13, the percentage difference between the two case studies for all three methods is less than $1 \%$. Hence, both case studies are presenting similar results. However, the EC per unit of item calculated using SCEEM, Blackbook and eToolLCD in individual case studies is different from one another. SCEEM uses a first principles-based value addition method to estimate EC emissions in CSCs accurately. Hence, using SCEEM for EC estimating is the most recommended method to estimate EC in CSCs accurately. This paper presents the findings of an ongoing study. The methodology, SCEEM introduced in this study is subsequently used to develop the blockchain-based EC estimating system to accurately estimate EC in CSCs. 
Table 12. EC values calculated using SCEEM, Blackbook and eToolLCD for data collected from contractor: Case Study 1 vs. Case Study 2.

\begin{tabular}{|c|c|c|c|c|c|c|c|c|c|c|c|c|c|c|c|c|}
\hline \multirow{3}{*}{ Item } & \multicolumn{6}{|c|}{ Case Study 1 Data Set 1} & \multicolumn{7}{|c|}{ Case Study 2 Data Set 3} & \multirow{2}{*}{\multicolumn{3}{|c|}{ Difference \% }} \\
\hline & \multirow{2}{*}{ Description } & \multirow{2}{*}{ Quantity } & \multirow{2}{*}{ Unit } & \multicolumn{3}{|c|}{$\mathrm{EC}\left(\mathrm{kgCO}_{2} \mathrm{e}\right)$} & \multirow{2}{*}{ Item } & \multirow{2}{*}{ Description } & \multirow{2}{*}{ Quantity } & \multirow{2}{*}{ Unit } & \multicolumn{3}{|c|}{$\mathrm{EC}\left(\mathrm{kgCO}_{2} \mathrm{e}\right)$} & & & \\
\hline & & & & SCEEM & Blackbook & eToolLCD & & & & & SCEEM & Blackbook & eToolLCD & SCEEM & Blackbook & eToolLCD \\
\hline A & $\begin{array}{l}\text { Strip topsoil } \\
(200 \mathrm{~mm}) \text { and } \\
\text { stockpile on site }\end{array}$ & 401,724 & $\mathrm{~m}^{2}$ & 0.19 & 0.36 & 0.97 & A & $\begin{array}{l}\text { Strip topsoil } \\
(250 \mathrm{~mm}) \text { and } \\
\text { stockpile on site }\end{array}$ & 97,434 & $\mathrm{~m}^{2}$ & 0.24 & 0.44 & 1.22 & 25.36 & 24.91 & 25.00 \\
\hline B & $\begin{array}{l}\text { Cart from } \\
\text { stockpile and } \\
\text { spread topsoil } \\
(200 \mathrm{~mm})\end{array}$ & 314,022 & $\mathrm{~m}^{2}$ & 0.23 & 0.11 & 0.42 & B & $\begin{array}{l}\text { Cart from } \\
\text { stockpile and } \\
\text { spread topsoil } \\
(300 \mathrm{~mm})\end{array}$ & 78,925 & $\mathrm{~m}^{2}$ & 0.33 & 0.11 & 0.63 & 45.02 & -0.36 & 50.00 \\
\hline C & $\begin{array}{l}\text { Cart from } \\
\text { stockpile and } \\
\text { spread topsoil } \\
(100 \mathrm{~mm})\end{array}$ & 29,695 & $\mathrm{~m}^{2}$ & 0.31 & 0.11 & 0.21 & $\mathrm{C}$ & $\begin{array}{l}\text { Cart from } \\
\text { stockpile and } \\
\text { spread topsoil } \\
(150 \mathrm{~mm})\end{array}$ & 12,513 & $\mathrm{~m}^{2}$ & 0.47 & 0.11 & 0.32 & 51.07 & -0.37 & 50.01 \\
\hline $\mathrm{D}$ & Cut to onsite fill & 189,105 & $\mathrm{~m}^{3}$ & 2.39 & 2.58 & 4.86 & $\mathrm{D}$ & Cut to onsite fill & 7398 & $\mathrm{~m}^{3}$ & 2.41 & 2.58 & 4.86 & 0.65 & 0.01 & 0.00 \\
\hline E & $\begin{array}{l}\text { Cut and stockpile } \\
\text { onsite }\end{array}$ & 158,384 & $\mathrm{~m}^{3}$ & 1.01 & 2.13 & 4.86 & & & & & & & & & & \\
\hline F & $\begin{array}{l}\text { Excavate, backfill } \\
\text { and compact } \\
\text { trenches }\end{array}$ & 16,714 & $\mathrm{~m}^{3}$ & 4.61 & 5.75 & 13.75 & $\mathrm{E}$ & $\begin{array}{l}\text { Excavate, backfill } \\
\text { and compact } \\
\text { trenches }\end{array}$ & 1899 & $\mathrm{~m}^{3}$ & 4.38 & 5.75 & 13.75 & -4.89 & 0.00 & 0.00 \\
\hline G & $\begin{array}{l}\text { Cart surplus } \\
\text { materials to } \\
\text { stockpile }\end{array}$ & 7713 & $\mathrm{~m}^{3}$ & 2.40 & 2.91 & 4.86 & F & $\begin{array}{l}\text { Cart surplus } \\
\text { materials to } \\
\text { stockpile }\end{array}$ & 1688 & $\mathrm{~m}^{3}$ & 2.39 & 2.91 & 4.86 & -0.36 & 0.02 & 0.00 \\
\hline
\end{tabular}


Table 13. EC values calculated using SCEEM, Blackbook and eToolLCD for the CSC of installation of stormwater pipes: Case Study 1 vs. Case Study 2.

\begin{tabular}{|c|c|c|c|c|c|c|c|c|c|}
\hline \multirow{3}{*}{ Description } & \multicolumn{6}{|c|}{$\mathrm{EC} /$ Unit $\left(\mathrm{kgCO}_{2} \mathrm{e} /\right.$ Unit $)$} & \multirow{2}{*}{\multicolumn{3}{|c|}{ Difference (\%) }} \\
\hline & \multicolumn{3}{|c|}{ Case Study 1 (Data Set 1 and Data Set 2$)$} & \multicolumn{3}{|c|}{ Case Study 2 (Data Set 3 and Data Set 4) } & & & \\
\hline & SCEEM & Blackbook & eToolLCD & SCEEM & Blackbook & eToolLCD & SCEEM & Blackbook & eToolLCD \\
\hline $\begin{array}{l}\text { Manufacturing, } \\
\text { transportation and } \\
\text { installation of } \\
\text { stormwater pipes }\end{array}$ & 199.22 & 148.21 & 184.59 & 199.07 & 148.23 & 184.57 & -0.07 & 0.02 & -0.01 \\
\hline
\end{tabular}

\section{Conclusions}

Though there are several EC estimating databases and tools available, their accuracy is quite questionable. As a result, SCEEM, a novel methodology, has been introduced to accurately estimate EC. This paper reviews SCEEM and compares EC estimates prepared using SCEEM with other EC databases and tools.

Initially, the conceptual method, SCEEM was reviewed and the calculation process to estimate EC using SCEEM was identified. The civil construction works related to two housing development projects were considered to evaluate the proof of concept of the study as its scope comprise a limited number of activities and CSCs compared with other areas and other types of projects. EC estimating using SCEEM was carried out using the data collected from the selected two case studies. Subsequently, the estimated EC values were compared with Blackbook and eToolLCD to evaluate their accuracy as discussed in Section 3.1. However, the results demonstrated in Tables 8 and 10 for the data collected from the contractor, revealed that though some of the EC values calculated using Blackbook were somewhat closer to EC values calculated using SCEEM, most of the EC values calculated using eToolLCD were massively different from the EC values calculated using SCEEM. According to Tables 9 and 11, the results for the EC emissions calculated for the CSC related to installation of stormwater pipes indicated that EC values calculated using Blackbook were $26 \%$ lesser than SCEEM while EC values calculated using eToolLCD was 7\% higher than EC values calculated using SCEEM, where both case studies indicated similar results. The cross-case analysis (Table 13) concluded this result. The cross-case analysis carried out between the two case studies for the EC values calculated for the system boundary of site-to-end of construction also presented similar results. Some of the items indicated higher percentage differences for SCEEM, Blackbook and eToolLCD where it was impacted by the topsoil thickness. Otherwise, the results produced by SCEEM were mostly similar, emphasising that SCEEM provides consistent results and making it a suitable method to estimate EC accurately.

The method SCEEM introduced in this study resolves issues in existing carbon estimating databases or tools and contributes to knowledge providing the basis for accurate estimation of EC in construction projects, which could be used by researchers, practitioners and policymakers, among others. In addition to the road map introduced by Green Building Council Australia to reduce the EC emissions, EC estimating could be mandated to assess and reduce EC emissions in construction.

Due to the usage of two case studies, it is difficult to generalise the findings of this study. However, SCEEM could be used in other similar studies to estimate EC emissions of various EC contributors using a quantitative approach and to carry out comparisons in other types of projects. Subsequent to this study, an EC estimating blockchain-based prototype system is being developed based on SCEEM. Though there were several limitations/issues in the manual estimation of EC using SCEEM, the blockchain-based EC estimating system could eliminate these issues as real-time data are entered into the system by the actual EC contributors themselves. This blockchain-based system could be used by the stakeholders in the construction industry to capture the EC transactions and estimate EC in construction projects. 
Author Contributions: Conceptualization, M.N.N.R., S.P., S.S. and X.J.; data curation, M.N.N.R.; formal analysis, M.N.N.R.; methodology, M.N.N.R., S.P., S.S. and X.J.; project administration, S.P.; supervision, S.P., S.S. and X.J.; writing—original draft, M.N.N.R.; writing—review and editing, M.N.N.R., S.P., S.S. and X.J. All authors have read and agreed to the published version of the manuscript.

Funding: This research is funded by the Research Training Program Scholarship provided to Western Sydney University by the Commonwealth Government of Australia and in-kind funding from the Centre for Smart Modern Construction (c4SMC) and its collaborators.

Institutional Review Board Statement: The study was conducted according to the guidelines of the National Statement on Ethical Conduct in Human Research 2007 (Updated 2018). Ethical approval for this project has been granted by the Western Sydney University Human Research Ethics Committee. (HREC Approval Number: H13394 and Date of Approval: 21 August 2019).

Informed Consent Statement: Informed consent was obtained from all participants involved in the study.

Data Availability Statement: Not applicable.

Acknowledgments: The authors acknowledge the industry collaborators for providing the required data, which were analysed to produce this research paper and Centre for Smart Modern Construction (c4SMC) for the provision of necessary infrastructure for the research.

Conflicts of Interest: The authors declare no conflict of interest.

\section{References}

1. Langston, C. The role of coordinate-based decision-making in the evaluation of sustainable built environments. Constr. Manag. Econ. 2013, 31, 62-77. [CrossRef]

2. Karl, T.R.; Melillo, J.M.; Peterson, T.C. Global Climate Change Impacts in the United States: Global Climate Change Impacts in the United States; Cambridge University Press: Cambridge, UK, 2009.

3. United Nations Environment Programme. Buildings and Climate Change: Summary for Decision-Makers; United Nations Environment Programme: Paris, France, 2009.

4. Huang, B.; Xing, K.; Pullen, S. Carbon assessment for urban precincts: Integrated model and case studies. Energy Build. 2017, 153, 111-125. [CrossRef]

5. Committee on Climate Change. Fourth Carbon Budget Review-Part 2-The Cost Effective Path to the 2050 Target; Committee on Climate Change: London, UK, 2013; pp. 1-90.

6. Teng, Y.; Li, K.; Pan, W.; Ng, T. Reducing building life cycle carbon emissions through prefabrication: Evidence from and gaps in empirical studies. Build. Environ. 2018, 132, 125-136. [CrossRef]

7. Ashworth, A.; Perera, S. Economics of Sustainability and Carbon Estimating: Cost Studies of Buildings; CRC Press: London, UK, 2015; pp. 491-529.

8. $\quad$ RICS. Methodology to Calculate Embodied Carbon of Materials; RICS: London, UK, 2012.

9. Rodrigo, M.N.N.; Perera, S.; Senaratne, S.; Jin, X. Embodied carbon mitigation strategies in the construction industry. In Proceedings of the CIB World Building Congress, Hong Kong, 17-21 June 2019.

10. Green Building Council Australia. A Carbon Positive Roadmap for the Built Environment. Available online: https://new.gbca org.au/rate/green-star-strategy/carbon-climate-change/ (accessed on 15 January 2020).

11. Moncaster, A.M.; Symons, K.E. A method and tool for 'cradle to grave' embodied carbon and energy impacts of UK buildings in compliance with the new TC350 standards. Energy Build. 2013, 66, 514-523. [CrossRef]

12. Pomponi, F.; Moncaster, A. Embodied carbon mitigation and reduction in the built environment-What does the evidence say? J. Environ. Manag. 2016, 181, 687-700. [CrossRef]

13. Rodrigo, M.N.N.; Perera, S.; Senaratne, S.; Jin, X. Conceptual model on estimating embodied carbon in construction supply chains using value chain and blockchain. In Proceeding of the AUBEA Conference, Noosa, Australia, 6-8 November 2019.

14. Available online: https://www.etoolglobal.com/wp-content/uploads/2012/10/Embodied-Energy-Paper-Richard-Haynes.pdf (accessed on 15 January 2020).

15. Giesekam, J.; Barrett, J.R.; Taylor, P. Construction sector views on low carbon building materials. Build. Res. Inf. 2015, 44, 423-444. [CrossRef]

16. Lutzkendorf, T.; Foliente, G.; Balouktsi, M.; Wiberg, A.H. Net-zero buildings: Incorporating embodied impacts. Build. Res. Inf. 2014, 43, 62-81. [CrossRef]

17. Nawarathna, A.; Siriwardana, M.; Alwan, Z. Embodied Carbon as a Material Selection Criterion: Insights from Sri Lankan Construction Sector. Sustainability 2021, 13, 2202. [CrossRef]

18. RICS. Methodology to Calculate Embodied Carbon; RICS: London, UK, 2014.

19. Victoria, M.F.; Perera, S. Parametric embodied carbon prediction model for early stage estimating. Energy Build. 2018, 168, 106-119. [CrossRef] 
20. Mao, C.; Shen, Q.; Shen, L.; Tang, L. Comparative study of greenhouse gas emissions between off-site prefabrication and conventional construction methods: Two case studies of residential projects. Energy Build. 2013, 66, 165-176. [CrossRef]

21. Schwartz, Y.; Raslan, R.; Mumovic, D. The life cycle carbon footprint of refurbished and new buildings-A systematic review of case studies. Renew. Sustain. Energy Rev. 2018, 81, 231-241. [CrossRef]

22. Seo, S.; Hwang, Y. Estimation of $\mathrm{CO}_{2}$ emissions in Life Cycle of Residential Buildings. J. Constr. Eng. 2001, 127, 414-418. [CrossRef]

23. Crawford, R.H.; Stephan, A.; Schmidt, M. An Australian Perspective. In Embodied Carbon in Buildings; Pomponi, F., Ed.; Springer: New York, NY, SUA, 2018; pp. 393-416.

24. Toller, S.; Carlsson, A.; Wadeskog, A.; Miliutenko, S.; Finnveden, G. Indicators for environmental monitoring of the Swedish building and real estate management sector. Build. Res. Inf. 2013, 41, 146-155. [CrossRef]

25. Xu, P.; Shao, L.; Geng, Z.; Guo, M.; Wei, Z.; Wu, Z. Consumption-Based Carbon Emissions of Tianjin Based on Multi-Scale Input-Output Analysis. Sustainability 2019, 11, 6270. [CrossRef]

26. Xie, W.; Hu, S.; Li, F.; Cao, X.; Tang, Z. Carbon and Water Footprints of Tibet: Spatial Pattern and Trend Analysis. Sustainability 2020, 12, 3294. [CrossRef]

27. Yan, H.; Shen, Q.; Fan, L.C.H.; Wang, Y.; Zhang, L. Greenhouse gas emissions in building construction: A case study of One Peking in Hong Kong. Build. Environ. 2010, 45, 949-955. [CrossRef]

28. Wang, Y.; Wang, W.; Mao, G.; Cai, H.; Zuo, J.; Wang, L.; Zhao, P. Industrial $\mathrm{CO}_{2}$ emissions in China based on the hypothetical extraction method: Linkage analysis. Energy Policy 2013, 62, 1238-1244. [CrossRef]

29. Yu, M.; Wiedmann, T.; Crawford, R.; Tait, C. The Carbon Footprint of Australia's Construction Sector. In Proceedings of the International High-Performance Built Environment Conference-A Sustainable Built Environment Conference (SBE16), Sydney, Australia, 17-18 November 2016.

30. Huang, L.; Bohne, R.A. Embodied air emissions in Norway's construction sector: Input-output analysis. Build. Res. Inf. 2012, 40, 581-591. [CrossRef]

31. Dixit, M.K. Embodied energy and cost of building materials: Correlation analysis. Build. Res. Inf. 2016, 45, 508-523. [CrossRef]

32. Teh, S.H.; Wiedmann, T.; Castel, A.; de Burgh, J. Hybrid life cycle assessment of greenhouse gas emissions from cement, concrete and geopolymer concrete in Australia. J. Clean. Prod. 2017, 152, 312-320. [CrossRef]

33. Teh, S.H.; Wiedmann, T.; Moore, S. Mixed-unit hybrid life cycle assessment applied to the recycling of construction materials. J. Econ. Struct. 2018, 7, 13. [CrossRef]

34. Hammond, G.P.; Jones, C.I. Embodied energy and carbon in construction materials. Proc. Inst. Civ. Eng. Energy 2008, 161, 87-98. [CrossRef]

35. Ekundayo, D.O.; Babatunde, S.O.; Ekundayo, A.; Perera, S.; Udeaja, C. Life cycle carbon emissions and comparative evaluation of selected open source UK embodied carbon counting tools. Constr. Econ. Build. 2019, 19, 220-242. [CrossRef]

36. Franklin, A. Volume 2-Major Works. In Hutchins UK Building Blackbook: The Capital Cost and Embodied $\mathrm{CO}_{2} \mathrm{Guide}$; Franklin and Andrew Ltd.: London, UK, 2010.

37. Available online: http://ecdb.wrap.org.uk/About.aspx (accessed on 2 August 2018).

38. Frischknecht, R.; Rebitzer, G. The ecoinvent database system: A comprehensive web-based LCA database. J. Clean. Prod. 2005, 13, 1337-1343. [CrossRef]

39. AusLCI Database. Available online: https://www.lifecycles.com.au/auslci-database (accessed on 22 April 2020).

40. Crawford, R.H.; Stephan, A.; Prideaux, F. Environmental Performance in Construction (EPiC) Database; The University of Melbourne: Melbourne, Australia, 2019.

41. The Footprint Company. Available online: https:/ / footprintgreenbook.com (accessed on 19 May 2020).

42. Available online: https://www.mottmac.com/article/540/mott-macdonald-launches-capit-worlds-first-su (accessed on 1 August 2018).

43. AFD. The AFD Carbon Footprint Tool for Projects; AFD: Paris, France, 2017.

44. Fu, F.; Luo, H.; Zhong, H.; Hill, A. Development of a Carbon Emission Calculations System for Optimizing Building Plan Based on the LCA Framework. Math. Probl. Eng. 2014, 2014, 1-13. [CrossRef]

45. Tally. Know Your Impact. Available online: https:// choosetally.com/ (accessed on 28 May 2021).

46. SimaPro. LCA Software to Help You Drive Change. Available online: https://simapro.com/ (accessed on 9 September 2018).

47. ETool. Available online: https:/ / etoolglobal.com/ (accessed on 21 May 2019).

48. UNSW. Step-by-Step Manual for Embodied Carbon Explorer (ECE) Tool Analysis; UNSW: Sydney, Australia, 2019.

49. The Footprint Company. The Footprint Calculator; The Footprint Company: Waverley, Australia, 2019; pp. 1-5.

50. Sinha, R.; Lennartsson, M.; Frostell, B. Environmental footprint assessment of building structures: A comparative study. Build. Environ. 2016, 104, 162-171. [CrossRef]

51. Lee, D.; Kang, G.; Nam, C.; Cho, H.; Kang, K.I. Stochastic Analysis of Embodied Carbon Dioxide Emissions Considering Variability of Construction Sites. Sustainability 2019, 11, 4215. [CrossRef]

52. $\mathrm{Hu}, \mathrm{M}$. A Building Life-Cycle Embodied Performance Index-The Relationship between Embodied Energy, Embodied Carbon and Environmental Impact. Energies 2020, 13, 1905. [CrossRef]

53. Rodrigo, M.N.N.; Perera, S.; Senaratne, S.; Jin, X. Potential Application of Blockchain Technology for Embodied Carbon Estimating in Construction Supply Chains. Buildings 2020, 10, 140. [CrossRef] 
54. Fernando, N.G.; Ekundayo, D.O.; Victoria, M.F. Embodied carbon emissions of buildings: A case study of an apartment building in the UK. In Proceedings of the 7th World Construction Symposium 2018: Built Asset Sustainability; Rethinking Design, Construction and Operation, Colombo, Sri Lanka, 29 June-1 July 2018.

55. Victoria, M.F.; Perera, S.; Davies, A. Developing an early design stage embodied carbon prediction model: A case study. In Proceedings of the 31st Annual ARCOM Conference, Lincoln, UK, 7-9 September 2015.

56. Fouche, M.; Crawford, R. The Australian construction industry's approach to embodied carbon assessment: A scoping study. In Proceedings of the 49th International Conference of the Architectural Science Association: Living and Learning, Research for a Better Built Environment, Melbourne, Australia, 2-4 December 2015.

57. Department of the Environment and Energy. National Greenhouse Accounts Factors; Department of the Environment and Energy: Sydney, Australia, 2017.

58. EPD Australasia. Available online: https:/ / epd-australasia.com/ (accessed on 19 March 2020).

59. Flower, D.J.M.; Sanjayan, J.G. Green house gas emissions due to concrete manufacture. Int. J. Life Cycle Assess. 2007, 12, 282-288. [CrossRef]

60. Repurpose It: Environment Product Declaration for Repurpose It-Recovered Mineral Aggregates. Available online: http: / / epd-australasia.com/wp-content/uploads/2020/03/Repurpose-It-EPD-Recovered-Mineral-Aggregates-v1-0.pdf (accessed on 19 May 2020).

61. Holcim. Holcim Ultracem Environment Product Declaration for General Purpose Portland Cement, Australia. 2019, pp. 1-19. Available online: https://www.holcim.co.nz/sites/newzealand/files/atoms/files/holcimepd19082019.pdf (accessed on 19 May 2020).

62. BlueScope Steel: Environment Product Declaration for Steel-Hot Rolled Coil, BlueScope Steel, Australia. 2020, pp. 1-24. Available online: http:/ / www.steel.com.au/articles/environmental-product-declarations (accessed on 24 August 2020). 